\title{
SLEEP- DISORDERED BREATHING IN CYSTIC FIBROSIS
}

\author{
AESHA JOBANPUTRA ${ }^{1}$, SUGEET JAGPAL ${ }^{1}$, OMAR AHMED ${ }^{1}$, TEODORO \\ SANTIAGO$^{1}$, and MAYA RAMAGOPAL ${ }^{2}$ \\ ${ }^{1}$ Rutgers The State University of New Jersey \\ ${ }^{2}$ Rutgers Robert Wood Johnson Medical School New Brunswick
}

May 18, 2020

\begin{abstract}
Sleep-disordered breathing is an underrecognized comorbidity in the cystic fibrosis (CF) population across the lifespan. Nocturnal hypoxia, obstructive sleep apnea (OSA), and nocturnal hypoventilation are respiratory abnormalities that occur commonly during sleep, and have deleterious consequences to quality of life in people with CF. Effective screening for these abnormalities is needed to allow for the timely initiation of treatment. Lack of treatment leads to worse pulmonary, cardiovascular, and metabolic outcomes in patients. In this review, we give an overview of sleep-disordered breathing for the CF clinician, including definitions, treatment, and suggestions for future research. We strongly encourage the CF community to incorporate evaluation for sleep-disordered breathing, so that outcomes for the subset of the patients with coexisting sleep-disordered breathing improve.
\end{abstract}

\section{Introduction}

Given the well-recognized coexistence of sleep-disordered breathing and obstructive lung diseases such as COPD and asthma, it is not surprising that sleep-disordered breathing also coexists with cystic fibrosis $(\mathrm{CF}) \cdot{ }^{1-4}$ Sleep architecture, the cyclical pattern of sleep between different sleep stages, is similar in CF patients compared to normal controls; however, CF patients have impaired subjective sleep quality. ${ }^{5}$ Poor sleep quality can be due to upper airway disease such as sinus disease, structural lung disease, chronic cough, use of medications including opioids, and the prevalence of sleep-disordered breathing. ${ }^{6}$ Sleep-disordered breathing encompasses a broad spectrum of respiratory abnormalities during sleep, ranging from primary snoring, respiratory event related arousals (RERAs), nocturnal hypoxia, obstructive sleep apnea (OSA), and hypoventilation. Primary snoring does not have physiological consequences; however, other respiratory abnormalities during sleep, especially OSA, can have significant deleterious effects.

Untreated sleep-disordered breathing can adversely affect outcomes in patients with chronic lung disease ${ }^{7}$, and therefore it is essential that CF clinicians expeditiously screen, diagnose, and treat sleep-disordered breathing in the $\mathrm{CF}$ population. In this review, we focus on three clinically relevant categories of sleepdisordered breathing: nocturnal hypoxemia, obstructive sleep apnea, and nocturnal hypoventilation. ${ }^{8}$ We will also discuss proposed areas for future research, and suggest key practical take home points for the nonsleep trained $\mathrm{CF}$ clinician.

We acknowledge that other sleep disorders such as insomnia, periodic leg movements and circadian rhythm disturbances are prevalent in individuals with $\mathrm{CF}$, but these are outside the scope of this review. In addition, we will not be covering respiratory related arousals and central sleep apnea, as little is known about these conditions as it specifically applies to the CF population ${ }^{9}$.

\section{Significance of Sleep-disordered breathing in the CF population}


Insufficient sleep, which can be a consequence of sleep-disordered breathing, has been recognized as a risk factor for mortality in young adults and is of high concern ${ }^{10}$. Sleep complaints occur in $40 \%$ of children with CF, with $70 \%$ reporting daytime sleepiness ${ }^{11}$. It is important to note that neither malnutrition nor respiratory muscle weakness are necessary to develop hypoxemia or hypercapnia during sleep, putting a larger portion of the CF population at risk for sleep-disordered breathing than was originally believed ${ }^{12}$. Obstructive sleep apnea in particular is noted to have a high prevalence in CF children, and OSA can lead to deteriorating school performance, failure to thrive, and worsening lung function ${ }^{13}$. Besides, sleep-disordered breathing in children with chronic pulmonary diseases including $\mathrm{CF}$ can lead to neurocognitive effects that hamper development $\mathrm{s}^{14}$. Therefore, it is important that $\mathrm{CF}$ pediatric providers are aware of the impact of sleep-disordered breathing in their patients.

As the CF population overall has improved longevity, medical conditions that are associated with sleepdisordered breathing such as obesity, diabetes, and cardiovascular diseases are emerging. ${ }^{15-18}$ It is

important to acknowledge that the adult population with $\mathrm{CF}$ has exceeded the pediatric population since 2015, and increased age is known to be a major risk factors for the development of sleep-disordered breathing. ${ }^{19,20}$ Improvement in genetic diagnosis of $\mathrm{CF}$ has also led to milder phenotypes of $\mathrm{CF}$ being recognized in later life ${ }^{21}$ when patients are at risk for other age related comorbidities. Also, as this population gains weight, the risk for OSA in particular is increased. A study by Peppard et al. has shown that a $10 \%$ increase in weight increases the risk of OSA 6 -fold..$^{20}$ Cardiovascular complications

such as hypertension, coronary artery disease, and stroke have been described in adults with OSA ${ }^{22},{ }^{23},{ }^{24}$. Autonomic dysfunction in OSA is associated with impaired glucose tolerance ${ }^{25}$, and the implications

of the development of diabetes is well known to CF clinicians. In addition, fragmented sleep caused by sleepdisordered breathing is known to cause fatigue, which is highly prevalent in CF and negatively associated with wellbeing and emotional health ${ }^{26}$. The fragmented sleep that leads to fatigue is a result of frequent nocturnal awakenings. It has been shown that forced expiratory volume in 1 second $\left(\mathrm{FEV}_{1}\right)$ inversely correlates with the number of nocturnal awakenings, which means there is more fragmented sleep as lung function declines. ${ }^{27}$

Without question, the above concerns highlight that CF clinicians need to be looking for and treating sleep-disordered breathing in these patients.

\section{Sleep-disordered breathing: Screening tools and definition of key terms}

Presently, there are no screening guidelines for sleep-disordered breathing in pediatric or adult CF patients. Screening questionnaires and tools exist for obstructive sleep apnea (OSA) in the non-CF population, but there are no tools for screening for the rest of the spectrum of sleep-disordered breathing. Objective tests exist to diagnose nocturnal hypoxia, apneas, and nocturnal hypoventilation.

Nocturnal hypoxemia is defined as oxygen saturation [?] $90 \%$ in children and [?] $88 \%$ in adults for $>5$ minutes. As per the AASM definition, hypoventilation during sleep in children is defined as arterial $\mathrm{PCO}_{2}$ (or surrogate) being greater than $50 \mathrm{~mm} \mathrm{Hg}$ for more than $25 \%$ of total sleep time. For adults, sleep hypoventilation is scored when the arterial $\mathrm{PCO}_{2}$ (or surrogate) is $>55 \mathrm{~mm} \mathrm{Hg}$ for [?] 10 minutes or there is an increase in the arterial PCO2 (or surrogate) [?] $10 \mathrm{~mm} \mathrm{Hg}$ (in comparison to an awake supine value) to a value exceeding $50 \mathrm{~mm} \mathrm{Hg}$ for [?] 10 minutes. $^{8}$

Of all the sleep disordered breathing disorders, OSA has the most abundant tools and screening questionnaires, both for pediatric and adult populations. In the pediatric population, modified questionnaires and/or the presence of snoring are used for further evaluation of OSA. ${ }^{28}$ It has been recommended by the American Academy of Pediatrics that enquiring about snoring at each clinical visit may be a sensitive screening measure for OSA that is quick and easy to perform. ${ }^{28}$ In adults, multiple different tools are available for OSA screening, such as STOP-BANG, Berlin Criteria, and the Epworth Sleepiness Scale (ESS). ${ }^{29}$

In the pediatric population, obstructive apnea has been defined as a decrease in nasal pressure or oronasal 
thermal airflow [?] $90 \%$ of pre-event baseline for [?] 2 breaths with presence of respiratory effort. ${ }^{30}$ Hypopneas in the pediatric population are identified by a decrease in nasal pressure or oronasal thermal airflow [?] $30 \%$ of pre-event baseline for [?] 2 breaths with [?] 3\% oxygen desaturation from pre-event baseline or an associated arousal. The diagnostic criteria for OSA in children is the presence of [?] 1 obstructive apnea or hypopnea per hour of sleep (apnea-hypopnea index (AHI) [?] 1 per hour). ${ }^{8}$

In adults, obstructive apnea has been defined as a decrease in nasal pressure or oronasal thermal airflow [?] $90 \%$ of pre-event baseline for [?] 10 seconds with continued or increased inspiratory effort. ${ }^{30}$ Hypopneas are defined as decrease in nasal pressure or oronasal thermal airflow [?] $30 \%$ of pre-event baseline for [?] 10 seconds with [?] 3\% oxygen desaturation from pre-event baseline. ${ }^{30}$ The diagnostic criteria for OSA in adults is the presence of [?] 5 obstructive apneas or hypopneas per hour of sleep or per hour of monitoring (AHI [?] 5 per hour). ${ }^{8}$

Hypoventilation in sleep, defined by a decrease in minute ventilation, is normal in healthy controls and is more pronounced in those with lung disease. In rapid eye movement (REM) sleep, respiratory muscle function is reduced, during which diaphragm contraction is preserved, and minute ventilation can decrease more than $15 \%$ in this phase of sleep in normal individuals ${ }^{31}$. This decrease of respiratory muscle function in patients with lung disease is more pronounced ${ }^{7}$, and furthermore, patients with hyperinflation have decreased diaphragm contraction ${ }^{4,32}$. A decrease in minute ventilation while asleep can lead to hypercapnia.

\section{Diagnosis of Sleep-disordered Breathing}

The American Academy of Sleep Medicine (AASM) strongly recommends using objective testing to diagnose the entire spectrum sleep-disordered breathing and not relying solely on screening questionnaires, tools and prediction algorithms. ${ }^{29}$

Using oximetry alone is not valid for diagnosing sleep-disordered breathing as it will not diagnose hypercapnia and can underestimate the severity of sleep-disordered breathing. ${ }^{33}$ Actigraphy, which measures sleep parameters and the average motor activity over a period of days to weeks using a noninvasive accelerometer, shows evidence of poor and fragmented sleep in CF but does not allow for the diagnosis of nocturnal hypoxia, OSA, or nocturnal hypoventilation ${ }^{34}$. Home sleep apnea tests are not recommended in the CF population because they are limited to assessing the sleep-wake pattern but do not reveal other sleep disturbances.

The gold standard diagnostic test for sleep-disordered breathing in the CF population is an overnight, attended, in-laboratory polysomnography (PSG). ${ }^{33}$ A PSG is a noninvasive diagnostic test that monitors EEG to determine sleep staging, oronasal airflow and abdominal/chest wall movement to determine the presence of sleep disordered breathing, end-tidal or transcutaneous carbon dioxide $\left(\mathrm{CO}_{2}\right)$ monitoring to determine the presence of hypoventilation, in addition to several limb leads to evaluate for periodic limb movements (PLMs). ${ }^{30}$ In addition, there is video monitoring to evaluate for sleep movement disorders. ${ }^{30}$

The AASM recommends that PSG be used in patients with underlying cardiopulmonary disease, respiratory muscle weakness, hypoventilation, and/or chronic opioid use to diagnose sleep-disordered breathing. ${ }^{29}$ PSG will allow for the diagnosis of nocturnal hypoxia, obstructive sleep apnea, and nocturnal hypoventilation. Therefore, CF patients will benefit the most from PSG when sleep-disordered breathing is suspected.

\section{Nocturnal Hypoxia: Physiological Consequences in CF}

Nocturnal desaturation is common in CF, can be harmful, and often exists independently of obstructive sleep apnea. ${ }^{35}$ One proposed mechanism for hypoxemia is atelectasis of the distal airways leading to a ventilationperfusion (V-Q) mismatch. ${ }^{36}$ In addition, sleep hypoxemia and hypercapnia correlate with the degree of nocturnal ventilatory deficits seen with more severe lung disease in CF. ${ }^{37}$ Repeated episodes of hypoxia can lead to deleterious effects on the right heart and development of pulmonary hypertension. ${ }^{38}$ Also, it is important to note that the cystic fibrosis transmembrane conductance regulatory protein (CFTR) has been examined as a functional contributor to hypoxia induced pulmonary hypertension. ${ }^{39}$ Nocturnal desaturation in COPD patients has been shown to increase C-reactive protein, which can increase cardiovascular disease, but similar effects have not been demonstrated in the CF population. ${ }^{40}$ 
Isaiah et al found that the percent predicted $\mathrm{FEV}_{1}$ was the best predictor of sleep hypoxemia in children with CF referred for PSG. ${ }^{41}$ A threshold of FEV1 < $64 \%$ was seen to have good sensitivity and specificity to predict nocturnal hypoxemia by de Castro-Silva et al. ${ }^{36}$ Resting awake $\mathrm{SpO}_{2}$, when low, can be predictive of nocturnal oxygenation but studies have been unable to find a threshold that reliably excludes those that will not desaturate. ${ }^{38}$ Fauroux et al have found some correlation of nocturnal hypoxemia with daytime blood gases, reporting that daytime partial arterial oxygen pressure correlated with mean and minimal nocturnal $\mathrm{SpO}_{2} \cdot{ }^{37}$ Six minute walk test desaturation is not predictive of nocturnal desaturation. ${ }^{42}$ The current daytime predictors of nocturnal hypoxemia continue to be variable in their reliability, and many continue to follow the recommendation of Frangolias and colleagues to consider nocturnal pulse oximetry in patients with moderate to severe CF lung disease. ${ }^{38}$

It has been suggested that the first clinical action after diagnosing nocturnal hypoxemia is to optimize treatment of lung function. ${ }^{41}$ Treatment of pulmonary exacerbations in cystic fibrosis results in improvement of nocturnal hypoxemia, but awake saturation did not immediately return to normal. ${ }^{43}$ Salvatore and colleagues have demonstrated that nocturnal use of inhaled salmeterol in albuterol responsive CF patients can reduce nocturnal hypoxemia. ${ }^{44}$ In addition, it is important to note that nocturnal oxygen therapy used in isolation may increase $\mathrm{CO}_{2}$ and could have a negative impact. ${ }^{45}$

A Cochrane review evaluating short term oxygen use in advanced CF lung disease concluded that oxygen therapy during sleep and exercise improves oxygenation, but is associated with a modest hypercapnia ${ }^{46}$.

\section{Obstructive Sleep Apnea (OSA)}

In the spectrum ranging from snoring to respiratory event related arousals (RERAs) to OSA, OSA is the most pathologic. In a study with 63 children and adolescents with CF between the ages of 2 and 14 years, the prevalence of polysomnogram-identified OSA has been reported to be $55.6 \%{ }^{47}$ Similarly, a study by Spicuzza et al. demonstrated that $70 \%$ of the 40 children between the age of 6 months and 11 years with stable CF had OSA. ${ }^{13}$ Of note, in children without underlying lung disease, the prevalence of OSA has been reported to be $1 \%$ to $4 \%{ }^{8}$ Although both groups of children with OSA share common factors such as adenotonsillar hypertrophy, craniofacial abnormalities such as micrognathia or midfacial hypoplasia, the children with CF have increased chronic rhinosinusitis (CRS) ${ }^{8,47}$ Increased respiratory resistance and hypoventilation related to acute and chronic inflammation has been cited as a potential mechanism for upper airway obstruction. ${ }^{48}$

To our knowledge, there are no studies specifically examining the relationship between CF related CRS and OSA, however the literature surrounding non-CF CRS and OSA can be extrapolated to CF related CRS. CRS has been shown to be strongly associated with poor subjective sleep quality and unequivocally associated with OSA. ${ }^{49-51}$ With respect to the latter, Jiang et al found that up to $64.7 \%$ of adult patients with CRS had comorbid OSA on polysomnography (PSG). ${ }^{49}$ In contrast, Alt et al identified OSA in only $15 \%$ of adult patients with CRS. ${ }^{50}$ Mahdavinia et al. examined how CRS affects polysomnography findings in patients with comorbid OSA. They compared patients with both CRS and OSA to patients with OSA and without CRS, and found that the AHI (Apnea-Hypopnea Index )between the two groups was similar suggesting that CRS may not significantly impact AHI. ${ }^{52}$ The effect of CRS, if any, on OSA has been theorized to be related to increased nasal airway resistance and sequelae of chronic inflammation. ${ }^{53}$ It has also been posited that chronic post-nasal drainage associated with sino-nasal inflammation can induce inflammatory, obstructive changes in the upper airway including the soft palate and uvula. ${ }^{52}$

OSA is not known to be as common in adults as in the pediatric population with CF. In a cross-sectional study with 51 stable CF adults (mean age 25.1 years), only two CF patients (3.9\%) met the standard criteria for OSA. ${ }^{5}$ One major study in a non-CF population has reported prevalence rates in men and women as high as $24 \%$ and $9 \%$ respectively. ${ }^{8}$ Studies with adult CF patients have been limited due to the sample size, lack of diversity, lack of an older age group which potentially underestimates the prevalence. ${ }^{5}$

\section{Nocturnal Hypoventilation}

Hypoventilation occurs when alveolar ventilation does not result in sufficient oxygen uptake or carbon diox- 
ide output. Occasional nocturnal hypoxemia occurs in normal subjects without significant physiological consequences, however, in patients with $\mathrm{CF}$, normally occurring variations in gas exchange during sleep can be consequential with underlying advanced lung disease. Several mechanisms have been identified that may lead to hypoventilation in CF patients. Patients with CF have an increased incidence of kyphosis, which results in decreased compliance or elasticity of the chest wall ${ }^{54}$. In addition, CF patients are often malnourished and have hyperinflation. Though both malnutrition and hyperinflation should lead to respiratory muscle weakness in patients with moderate to severe lung disease, the findings are not substantiated ${ }^{12}$. In a study of 64 adults with mild to moderate lung disease, FEV1 $65 \pm 19 \%$, when compared to normal controls, these subjects had normal respiratory muscle strength as measured by PI/PE $\max ^{55}$. CF patients may also be at increased risk of hypoventilation due to opioid use that are often prescribed for pain control in advanced CF lung disease ${ }^{56}$. Finally, increased risk of sleep disordered breathing may also lead to nocturnal hypoventilation. In normal healthy individuals, during sleep there is an increase in upper airway obstruction and decrease in the central drive to breathe. In individuals with $\mathrm{CF}$, although V-Q mismatch may lead to nocturnal hypoxemia, the major contributor to gas exchange abnormalities results from hypoventilation ${ }^{37}$ . These findings were more pronounced during REM sleep, which is also associated with reduced minute ventilation mainly due to a decrease in tidal volume $e^{11,31}$.

\section{Treatment}

The common mainstays of management for sleep-disordered breathing include oxygen therapy and noninvasive ventilation (NIV) such as continuous positive airway pressure (CPAP), bilevel positive airway pressure (BiPAP) or more advanced therapy. Oxygen therapy alone, however, should be looked at with caution in our patient population as it may worsen hypoventilation ${ }^{57}$. In children, therapeutic options include surgical options such adentonsillectomy as first line treatment for OSA. Additional options for OSA in adults include oral devices, glossopharyngeal nerve stimulation, myofunctional therapy and positional devices ${ }^{58-60}$. Pharmacologic therapies for OSA, such as montelukast and nasal steroids have shown mixed results in pediatric and adult populations, with some benefit to montelukast being seen in children but not adults ${ }^{61,62}$.

There are no clear guidelines or recent literature available for treatment of isolated nocturnal hypoxemia. Although there are studies evaluating use of oxygen therapy based on daytime hypoxemia, studies treating based on nocturnal hypoxemia are sparse. ${ }^{63}$ Multiple older studies exist recommending caution with using oxygen therapy alone at night for treatment due to worsening hypercarbia. ${ }^{45,46}$ In a 12 -month randomized prospective trial, Milross et al. studied the long term effects of NIV, with or without oxygen and low flow oxygen on event free survival in adults with CF already diagnosed with nocturnal hypoxemia by a PSG. ${ }^{57}$ Events were defined as development of hypoventilation, lung transplantation, or death. ${ }^{57}$ They also followed for outcomes such as hospitalization, lung function, and health-related quality of life. ${ }^{57}$ Their aim was to determine if adults with $\mathrm{CF}$ and nocturnal desaturations were less likely to develop hypercapnia on low flow oxygen or non-invasive ventilation. ${ }^{57}$ They concluded that NIV with or without oxygen increased event free survival compared to treatment with oxygen alone. ${ }^{57}$ This emphasizes that CF providers need to use caution if prescribing oxygen therapy alone.

Noninvasive positive pressure ventilation is not completely new to the cystic fibrosis population, and has been successfully already been incorporated in the care plan for certain patients. In stable CF patients with awake hypercapnia, a six week trial of nocturnal noninvasive ventilation showed improved nocturnal hypoventilation and peak exercise capacity without improving lung function or awake hypercapnia ${ }^{64}$. Noninvasive ventilation has also been evaluated in cystic fibrosis patients as an adjunct to airway clearance techniques ${ }^{65,66}$ particularly in patients having trouble expectorating sputum. ${ }^{65}$ The rationale is that in patients with severe lung disease, airway clearance therapy results in energy expenditure and use of noninvasive ventilation could allow for decreased work of breathing and fatigue. ${ }^{67}$ In addition, noninvasive ventilation is used pre- lung transplant, and has been shown to slow the decline in lung function in this patient subset ${ }^{65}$. It stands to reason that patients prescribed noninvasive ventilation for sleep-disordered breathing may also have additional benefits such as improved airway clearance, increased peak exercise capacity, and a slower decline in lung function; however, dedicated studies looking at these outcomes are necessary. 


\section{Future Directions}

The sleep community is aware of the long-term consequences of untreated sleep-disordered breathing. Although few articles specifically look at untreated sleep apnea in the CF population, it is reasonable to extrapolate that the $\mathrm{CF}$ population is at risk for these consequences as well. Gastroesophageal reflux is associated with sleep-disordered breathing ${ }^{68}$, and this has well known effects on failure to thrive in the pediatric CF population. Cardiovascular complications such as hypertension, coronary artery disease, and stroke have been described in adults ${ }^{22} 2324$. Sleep-disordered breathing in other chronic lung disease patients has been associated with the development of sequelae such as pulmonary hypertension, hyperlipidemia, insulin resistance, increased susceptibility to certain infections, and increased inflammatory markers. ${ }^{69-75}$ Autonomic dysfunction in sleep apnea is associated with impaired glucose tolerance ${ }^{25}$, and the implications of the development of diabetes is well known to the CF provider community. All of these sequelae are known to affect the quality of life in $\mathrm{CF}$ patients ${ }^{76}$.

More research in CF specific sleep-disordered breathing is necessary to understand the natural course of sleep across the lifespan. This information could assist the CF community to develop best practices in screening, diagnosis, and treatment for sleep disordered breathing. The timing in disease course and lifespan to best implement screening tools for sleep is unknown. The impact of modulator therapy is expected to be beneficial for pulmonary outcomes, which should reduce rates of sleep-disordered breathing. However, modulators may also increase rates of obesity, and then paradoxically increase rates of sleep-disordered breathing. The long term sequelae of undiagnosed and therefore untreated sleep-disordered breathing may not be available to us at this time, but studies looking at the impact of improved screening and effective treatment evaluating outcome measures such as quality of life, improved lung function, CF exacerbations and hospitalizations, and development of chronic medical conditions would be highly informative in guiding management of these patients. Large studies such as this will inform future CF care, potentially leading to screening guidelines for sleep-disordered breathing.

\section{Conclusion}

We have described the significant impact of sleep-disordered breathing in the CF population. Underdiagnosis of sleep-disordered breathing leads to undertreatment, which adversely effects multiple outcomes in this patient population. More studies are needed to understand the best screening modalities and treatment options for CF patients. It is essential that our community closely look at this comorbidity, and build up our comfort in screening for and treating this condition. As we await future research, we can make the following recommendations with reasonable confidence:

(1) Pediatric CF clinicians should ask about snoring during routine visits.

(2) Existing screening questionnaires do not accurately guage sleep-disordered breathing in the CF population. (3) When evaluating for sleep-disordered breathing in the CF population, an in-lab PSG should be obtained rather than an HSAT. (4) CF clinicians should be cautious when prescribing oxygen alone for nocturnal hypoxia. (5) $\mathrm{CF}$ clinicians should be comfortable prescribing noninvasive ventilation for $\mathrm{CF}$ patients with sleep-disordered breathing.

\section{References}

1. Shawon MS, Perret JL, Senaratna CV, Lodge C, Hamilton GS, Dharmage SC. Current evidence on prevalence and clinical outcomes of co-morbid obstructive sleep apnea and chronic obstructive pulmonary disease: A systematic review. Sleep Med Rev. 2017;32:58-68.

2. Kong DL, Qin Z, Shen H, Jin HY, Wang W, Wang ZF. Association of Obstructive Sleep Apnea with Asthma: A Meta-Analysis. Sci Rep.2017;7(1):4088.

3. Teodorescu M, Barnet JH, Hagen EW, Palta M, Young TB, Peppard PE. Association between asthma and risk of developing obstructive sleep apnea. JAMA. 2015;313(2):156-164. 
4. Soler X, Gaio E, Powell FL, et al. High Prevalence of Obstructive Sleep Apnea in Patients with Moderate to Severe Chronic Obstructive Pulmonary Disease. Ann Am Thorac Soc. 2015;12(8):1219-1225.

5. Perin C, Fagondes SC, Casarotto FC, Pinotti AF, Menna Barreto SS, Dalcin Pde T. Sleep findings and predictors of sleep desaturation in adult cystic fibrosis patients. Sleep Breath.2012;16(4):1041-1048.

6. Milross MA, Piper AJ, Dobbin CJ, Bye PT, Grunstein RR. Sleep disordered breathing in cystic fibrosis. Sleep Med Rev.2004;8(4):295-308.

7. McNicholas WT, Hansson D, Schiza S, Grote L. Sleep in chronic respiratory disease: COPD and hypoventilation disorders. Eur Respir Rev. 2019;28(153).

8. American Academy of Sleep Medicine. International Classification of Sleep Disorders, 3rd Edition. Darien, IL: American Academy of Sleep Medicine, 2014.

9. Mohammadieh A, Sutherland K, Cistulli PA. Sleep disordered breathing: management update. Intern Med J. 2017;47(11):1241-1247.

10. Akerstedt T, Ghilotti F, Grotta A, Bellavia A, Lagerros YT, Bellocco R. Sleep duration, mortality and the influence of age. Eur J Epidemiol. 2017;32(10):881-891.

11. Naqvi SK, Sotelo C, Murry L, Simakajornboon N. Sleep architecture in children and adolescents with cystic fibrosis and the association with severity of lung disease. Sleep Breath. 2008;12(1):77-83.

12. Bradley S, Solin P, Wilson J, Johns D, Walters EH, Naughton MT. Hypoxemia and hypercapnia during exercise and sleep in patients with cystic fibrosis. Chest. 1999;116(3):647-654.

13. Spicuzza L, Sciuto C, Leonardi S, La Rosa M. Early occurrence of obstructive sleep apnea in infants and children with cystic fibrosis. Arch Pediatr Adolesc Med. 2012;166(12):1165-1169.

14. Bandla H, Splaingard M. Sleep problems in children with common medical disorders. Pediatr Clin North Am. 2004;51(1):203-227, viii.

15. Regard L, Lafoeste H, Martin C, Chassagnon G, Burgel PR. [Ageing with cystic fibrosis: Classical and emerging comorbidities in adults with cystic fibrosis]. Rev Pneumol Clin. 2018;74(5):279-291.

16. Litvin M, Yoon JC, Leey Casella J, Blackman SM, Brennan AL. Energy balance and obesity in individuals with cystic fibrosis. J Cyst Fibros. 2019;18 Suppl 2:S38-S47.

17. Harindhanavudhi T, Wang Q, Dunitz J, Moran A, Moheet A. Prevalence and factors associated with overweight and obesity in adults with cystic fibrosis: A single-center analysis. J Cyst Fibros.2020;19(1):139145.

18. Hanna RM, Weiner DJ. Overweight and obesity in patients with cystic fibrosis: a center-based analysis. Pediatr Pulmonol.2015;50(1):35-41.

19. Young T, Palta M, Dempsey J, Peppard PE, Nieto FJ, Hla KM. Burden of sleep apnea: rationale, design, and major findings of the Wisconsin Sleep Cohort study. WMJ. 2009;108(5):246-249.

20. Peppard PE, Young T, Palta M, Dempsey J, Skatrud J. Longitudinal study of moderate weight change and sleep-disordered breathing.JAMA. 2000;284(23):3015-3021.

21. Sosnay PR, White TB, Farrell PM, et al. Diagnosis of Cystic Fibrosis in Nonscreened Populations. $J$ Pediatr. 2017;181S:S52-S57 e52.

22. Valham F, Mooe T, Rabben T, Stenlund H, Wiklund U, Franklin KA. Increased risk of stroke in patients with coronary artery disease and sleep apnea: a 10-year follow-up. Circulation.2008;118(9):955-960.

23. Nieto FJ, Young TB, Lind BK, et al. Association of sleep-disordered breathing, sleep apnea, and hypertension in a large community-based study. Sleep Heart Health Study. JAMA. 2000;283(14):1829-1836. 
24. Mooe T, Franklin KA, Holmstrom K, Rabben T, Wiklund U. Sleep-disordered breathing and coronary artery disease: long-term prognosis. Am J Respir Crit Care Med. 2001;164(10 Pt 1):1910-1913.

25. Peltier AC, Consens FB, Sheikh K, Wang L, Song Y, Russell JW. Autonomic dysfunction in obstructive sleep apnea is associated with impaired glucose regulation. Sleep Med. 2007;8(2):149-155.

26. Nap-van der Vlist MM, Burghard M, Hulzebos HJ, et al. Prevalence of severe fatigue among adults with cystic fibrosis: A single center study.J Cyst Fibros. 2018;17(3):368-374.

27. Piper AJ. Sleep and Breathing in Cystic Fibrosis. Totowa, NJ: Humana Press; 2012.

28. Marcus CL, Brooks LJ, Draper KA, et al. Diagnosis and management of childhood obstructive sleep apnea syndrome. Pediatrics.2012;130(3):e714-755.

29. Kapur VK, Auckley DH, Chowdhuri S, et al. Clinical Practice Guideline for Diagnostic Testing for Adult Obstructive Sleep Apnea: An American Academy of Sleep Medicine Clinical Practice Guideline. J Clin Sleep Med. 2017;13(3):479-504.

30. Berry RB, Brooks R, Gamaldo C, et al. AASM Scoring Manual Updates for 2017 (Version 2.4). J Clin Sleep Med. 2017;13(5):665-666.

31. Douglas NJ, White DP, Pickett CK, Weil JV, Zwillich CW. Respiration during sleep in normal man. Thorax. 1982;37(11):840-844.

32. White JE, Drinnan MJ, Smithson AJ, Griffiths CJ, Gibson GJ. Respiratory muscle activity during rapid eye movement (REM) sleep in patients with chronic obstructive pulmonary disease. Thorax.1995;50(4):376382.

33. Kirk V, Baughn J, D'Andrea L, et al. American Academy of Sleep Medicine Position Paper for the Use of a Home Sleep Apnea Test for the Diagnosis of OSA in Children. J Clin Sleep Med.2017;13(10):1199-1203.

34. Reiter J, Gileles-Hillel A, Cohen-Cymberknoh M, et al. Sleep disorders in cystic fibrosis: A systematic review and meta-analysis.Sleep Med Rev. 2020;51:101279.

35. Schidlow DV, Taussig LM, Knowles MR. Cystic Fibrosis Foundation consensus conference report on pulmonary complications of cystic fibrosis. Pediatr Pulmonol. 1993;15(3):187-198.

36. de Castro-Silva C, de Bruin VM, Cavalcante AG, Bittencourt LR, de Bruin PF. Nocturnal hypoxia and sleep disturbances in cystic fibrosis.Pediatr Pulmonol. 2009;44(11):1143-1150.

37. Fauroux B, Pepin JL, Boelle PY, et al. Sleep quality and nocturnal hypoxaemia and hypercapnia in children and young adults with cystic fibrosis. Arch Dis Child. 2012;97(11):960-966.

38. Frangolias DD, Wilcox PG. Predictability of oxygen desaturation during sleep in patients with cystic fibrosis : clinical, spirometric, and exercise parameters. Chest. 2001;119(2):434-441.

39. Tabeling C, Yu H, Wang L, et al. CFTR and sphingolipids mediate hypoxic pulmonary vasoconstriction. Proc Natl Acad Sci U S A.2015;112(13):E1614-1623.

40. Macrea MM, Owens RL, Martin T, Smith D, Oursler KK, Malhotra A. The effect of isolated nocturnal oxygen desaturations on serum hs-CRP and IL-6 in patients with chronic obstructive pulmonary disease. Clin Respir J. 2019;13(2):120-124.

41. Isaiah A, Daher A, Sharma PB, Naqvi K, Mitchell RB. Predictors of sleep hypoxemia in children with cystic fibrosis. Pediatr Pulmonol. 2019;54(3):273-279.

42. Gomez Punter RM, Giron Moreno RM, Vazquez Espinosa E, et al. Desaturations During 6-Minute Walk Test and Predicting Nocturnal Desaturations in Adult Subjects With Cystic Fibrosis. Respir Care. 2019;64(1):48-54. 
43. Allen MB, Mellon AF, Simmonds EJ, Page RL, Littlewood JM. Changes in nocturnal oximetry after treatment of exacerbations in cystic fibrosis.Arch Dis Child. 1993;69(2):197-201.

44. Salvatore D, D'Andria M. Effects of salmeterol on arterial oxyhemoglobin saturations in patients with cystic fibrosis.Pediatr Pulmonol. 2002;34(1):11-15.

45. Gozal D. Nocturnal ventilatory support in patients with cystic fibrosis: comparison with supplemental oxygen. Eur Respir J.1997;10(9):1999-2003.

46. Elphick HE, Mallory G. Oxygen therapy for cystic fibrosis.Cochrane Database Syst Rev. 2013(7):CD003884.

47. Ramos RT, Salles C, Gregorio PB, et al. Evaluation of the upper airway in children and adolescents with cystic fibrosis and obstructive sleep apnea syndrome. Int J Pediatr Otorhinolaryngol.2009;73(12):1780-1785.

48. Villa MP, Pagani J, Lucidi V, Palamides S, Ronchetti R. Nocturnal oximetry in infants with cystic fibrosis. Arch Dis Child.2001;84(1):50-54.

49. Jiang RS, Liang KL, Hsin CH, Su MC. The impact of chronic rhinosinusitis on sleep-disordered breathing. Rhinology.2016;54(1):75-79.

50. Alt JA, DeConde AS, Mace JC, Steele TO, Orlandi RR, Smith TL. Quality of Life in Patients With Chronic Rhinosinusitis and Sleep Dysfunction Undergoing Endoscopic Sinus Surgery: A Pilot Investigation of Comorbid Obstructive Sleep Apnea. JAMA Otolaryngol Head Neck Surg. 2015;141(10):873-881.

51. Mahdavinia M, Schleimer RP, Keshavarzian A. Sleep disruption in chronic rhinosinusitis. Expert Rev Anti Infect Ther.2017;15(5):457-465.

52. Mahdavinia M, Hui JW, Zitun M, et al. Patients with chronic rhinosinusitis and obstructive sleep apnea have increased paroxysmal limb movement. Am J Rhinol Allergy. 2018;32(2):94-97.

53. Alt JA, Smith TL. Chronic rhinosinusitis and sleep: a contemporary review. Int Forum Allergy Rhinol. 2013;3(11):941-949.

54. Henderson RC, Specter BB. Kyphosis and fractures in children and young adults with cystic fibrosis. $J$ Pediatr.1994;125(2):208-212.

55. Troosters T, Langer D, Vrijsen B, et al. Skeletal muscle weakness, exercise tolerance and physical activity in adults with cystic fibrosis.Eur Respir J. 2009;33(1):99-106.

56. Shook JE, Watkins WD, Camporesi EM. Differential roles of opioid receptors in respiration, respiratory disease, and opiate-induced respiratory depression. Am Rev Respir Dis. 1990;142(4):895-909.

57. Milross MA, Piper AJ, Dwyer TJ, et al. Non-invasive ventilation versus oxygen therapy in cystic fibrosis: A 12-month randomized trial.Respirology. 2019;24(12):1191-1197.

58. de Felicio CM, da Silva Dias FV, Trawitzki LVV. Obstructive sleep apnea: focus on myofunctional therapy. Nat Sci Sleep.2018;10:271-286.

59. Fleury Curado T, Oliven A, Sennes LU, Polotsky VY, Eisele D, Schwartz AR. Neurostimulation Treatment of OSA. Chest.2018;154(6):1435-1447.

60. Sarkissian L, Kitipornchai L, Cistulli P, Mackay SG. An update on the current management of adult obstructive sleep apnoea. Aust J Gen Pract. 2019;48(4):182-186.

61. Kuhle S, Urschitz MS. Anti-inflammatory medications for obstructive sleep apnea in children. Cochrane Database Syst Rev.2011(1):CD007074.

62. Smith DF, Sarber KM, Spiceland CP, Ishman SL, Augelli DM, Romaker AM. Effects of Medical Therapy on Mild Obstructive Sleep Apnea in Adult Patients. J Clin Sleep Med. 2019;15(7):979-983. 
63. Zinman R, Corey M, Coates AL, et al. Nocturnal home oxygen in the treatment of hypoxemic cystic fibrosis patients. J Pediatr.1989;114(3):368-377.

64. Young AC, Wilson JW, Kotsimbos TC, Naughton MT. Randomised placebo controlled trial of noninvasive ventilation for hypercapnia in cystic fibrosis. Thorax. 2008;63(1):72-77.

65. Moran F, Bradley JM, Piper AJ. Non-invasive ventilation for cystic fibrosis. Cochrane Database Syst Rev. 2017;2:CD002769.

66. Stanford G, Parrott H, Bilton D, Agent P. Positive pressure-analysing the effect of the addition of noninvasive ventilation (NIV) to home airway clearance techniques (ACT) in adult cystic fibrosis (CF) patients. Physiother Theory Pract.2015;31(4):270-274.

67. Rodriguez Hortal MC, Nygren-Bonnier M, Hjelte L. Non-invasive Ventilation as Airway Clearance Technique in Cystic Fibrosis.Physiother Res Int. 2017;22(3).

68. Valipour A, Makker HK, Hardy R, Emegbo S, Toma T, Spiro SG. Symptomatic gastroesophageal reflux in subjects with a breathing sleep disorder. Chest. 2002;121(6):1748-1753.

69. Irwin MR. Why sleep is important for health: a psychoneuroimmunology perspective. Annu Rev Psychol. 2015;66:143-172.

70. Park H, Tsai KM, Dahl RE, et al. Sleep and Inflammation During Adolescence. Psychosom Med. 2016;78(6):677-685.

71. Fernandez-Mendoza J, Baker JH, Vgontzas AN, Gaines J, Liao D, Bixler EO. Insomnia symptoms with objective short sleep duration are associated with systemic inflammation in adolescents. Brain Behav Immun.2017;61:110-116.

72. Kong AP, Wing YK, Choi KC, et al. Associations of sleep duration with obesity and serum lipid profile in children and adolescents. Sleep Med. 2011;12(7):659-665.

73. Bonuck K, Chervin RD, Howe LD. Sleep-disordered breathing, sleep duration, and childhood overweight: a longitudinal cohort study. J Pediatr. 2015;166(3):632-639.

74. Koren D, Gozal D, Philby MF, Bhattacharjee R, Kheirandish-Gozal L. Impact of obstructive sleep apnoea on insulin resistance in nonobese and obese children. Eur Respir J. 2016;47(4):1152-1161.

75. Rudnicka AR, Nightingale CM, Donin AS, et al. Sleep Duration and Risk of Type 2 Diabetes. Pediatrics. $2017 ; 140(3)$.

76. Voynow JA MM, Kelly A, Scanlin TF. Cystic Fibrosis. Vol Chapter 50, Volume 1. 5th Edition ed: McGraw Hill; 2015.

The authors thank Dr. Thomas Scanlin M.D. and Dr. Nisha Aurora M.D. for their review of the paper and valuable suggestions. The authors also thank the Cystic Fibrosis Foundation for the grant support of the Rutgers-Robert Wood Johnson Medical School pediatric and adult Cystic Fibrosis programs (CC 154). 